\title{
HIGH CURRENT PROPERTIES OF A MICROSPRING CONTACT FOR FLIP CHIP PACKAGING
}

\author{
Bowen Cheng ${ }^{1,2}$, Eugene M. Chow ${ }^{1}$,Dirk DeBruyker ${ }^{1}$, Ivan Shubin ${ }^{3}$, \\ John Cunningham ${ }^{3}$, Alex Chow ${ }^{3}$, Jing Shi ${ }^{3}$, Matt Giere ${ }^{3}$, Karl F. Böhringer ${ }^{2}$ \\ ${ }^{1}$ Palo Alto Research Center, Inc., Palo Alto, CA, USA \\ ${ }^{2}$ University of Washington, Seattle, WA, USA \\ ${ }^{3}$ Oracle, San Diego, CA, USA
}

\begin{abstract}
The high current properties of a micro spring pressure contact are characterized. The spring has large compliance $(>30$ $\mu \mathrm{m})$ compared to other packaging technologies and fits in a 180 $\mu \mathrm{m}$ pitch 2d array. At $250 \mathrm{~mA}$ and $65{ }^{\circ} \mathrm{C}$, daisy chains of 134 spring contacts in a silicon package show stable resistances and hotspot temperature rises of less than a degree. At $1 \mathrm{amp}$, failure near the spring tip or body is observed. Finite element modeling is performed to study the current distribution and provide failure mode insight. Simultaneous force and resistance measurements suggest there is no spring force softening. The results suggest a 10 mg $(100 \mu \mathrm{N})$ micro spring with large compliance can be reliable for high current applications.
\end{abstract}

\section{INTRODUCTION}

We are developing pressure contacts based on stressengineered thin film springs for next generation microelectronics flip-chip packaging. The springs are fabricated with wafer-scale processing, lithographically defined and self-assembled as they are released. Their advantages for flip chip packaging include: solder-free, low stress (helps low K dielectric problem), compliant (helps substrate thermal expansion mismatch) and scalable to fine pitch and low heights. They enable integrated test and packaging to address the known-good-die problem hindering high performance multi-chip modules. In addition to packaging, the technology has been used for a variety of MEMS devices, including coils, actuators, and AFM tips [1-5].

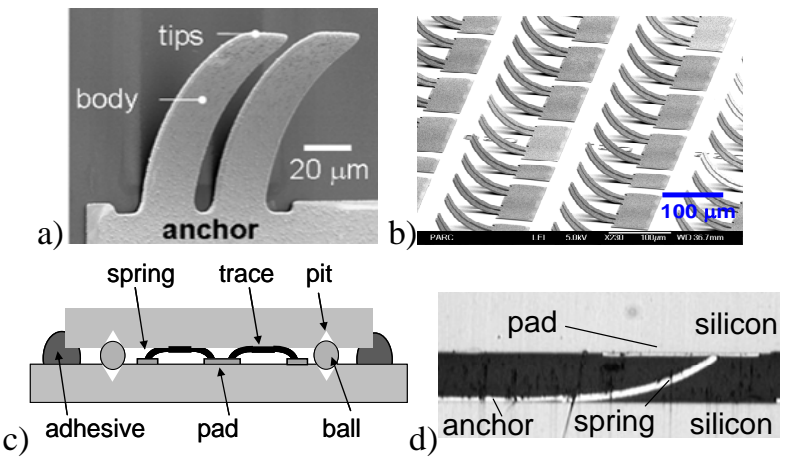

Figure 1. a) Fabricated contact consisting of a spring pair. b) array of contacts before assembly (>3000 per die on $14 \mathrm{~mm} \times 16$ $\mathrm{mm}$ die). c) Si package schematic and d) cross section (18 $\mu \mathrm{m}$ airgap). [6-7]

We previously reported on a spring designed to fit a standard flip-chip 2d grid $(180 \mu \mathrm{m} \times 180 \mu \mathrm{m})$ and achieve a unique combination of high compliance $(>30 \mu \mathrm{m})$ and low resistance ( $<100 \mathrm{~m} \Omega$ ). Thousands of springs on silicon substrates with integrated alignment pits were assembled into flip chip packages and shown to pass basic thermocycle and humidity reliability tests [6-7]. Each contact consisted of 2 springs, where each spring was $100 \mu \mathrm{m}$ long, $30 \mu \mathrm{m}$ wide, and $3.5 \mu \mathrm{m}$ thick. The middle $1 \mu \mathrm{m}$ core of the spring was composed of MoCr and the outer shell was $1.25 \mu \mathrm{m}$ of electroplated gold. Springs were isolated from the silicon substrate with $0.2 \mu \mathrm{m}$ nitride.

Current densities continue to increase with the steady downscaling of technologies. Current density has a square effect on joule heating, which may lead to failure mechanisms such as melting or chemical dislocation [8]. Electromigration induced failures, due to mass transport with electric fields, scales with current density [9]. Solder bump current densities can be $10^{3}-10^{4}$ $\mathrm{A} / \mathrm{cm}^{2}[10]$. Copper is low resistance and enables on-chip wiring to handle densities as high as $10^{5}-10^{6} \mathrm{~A} / \mathrm{cm}^{2}$ [11]. Gold also has low resistivity and can form stud bumps for flip chip packaging. Stud bumps at $5 \times 10^{4} \mathrm{~A} / \mathrm{cm}^{2}$ have been shown to be reliable [12]. Comparing current densities is challenging though, because there are many factors related to current carrying ability. The power dissipation and thermal design is critical, as temperature strongly affects failure. Mechanical stress levels also effect how the interconnect performs. For metallurgical bonds like solder and stud bumps, stresses can be very high, which reduces reliability.

Micro pressure contacts for packaging have not been studied at high current densities to our knowledge. In the future, we will package a custom prototype high power processor with these springs [13], which at maximum performance will consume 355 $\mathrm{W}$ and have an average of $90 \mathrm{~mA}$ per contact, corresponding to 7 $\times 10^{4} \mathrm{~A} / \mathrm{cm}^{2}$ average current density. This is less than what has been shown to be stable in previously reported MEMS switches (4 $\times 10^{5} \mathrm{~A} / \mathrm{cm}^{2}, 2$ watts), which also depends on gold, spring-based pressure contacts [14]. A spring for flip chip packaging, though, has different requirements than switches. The required compliance of our springs is much higher, typically tens of microns, as they need to accommodate large thermal expansion mismatches and nonplanarities between substrates. This means thinner metals need to be used, accacerbating cooling challenges. The spring interconnect should be reworkable with zero current, but does not have to survive billions of hot on/off cycles like some switches. Lateral scrubbing can induce wear in flip chip packages. Stiction is fatal for switches, but might not be an issue for a packaging application. Adsorbed film contamination is a risk for any gold surface. Both devices need to maintain force $(\sim 100 \mu \mathrm{N})$ to maintain electrical contact.

The aim of this work is to study the high current properties of the springs for high power flip chip packaging applications such as IC processors. In this paper, the contacts in silicon packages are experimentally tested with high current until failure is observed. Thermal imaging is performed to study the temperature distribution in the package. Modeling is then performed to give more insight into possible failure mechanisms. Finally force softening, a possible failure mechanism particularly important for springs, is studied.

\section{PACKAGE CURRENT TESTS}

The silicon-silicon package of springs (Figure 1) is heated and simultaneously subject to high current, to simulate a high 
power IC. Four-wire resistance structures of 134 contacts in series form a long daisy chain which is electrically monitored while the package is placed on a $65{ }^{\circ} \mathrm{C}$ thermoelectric heater (Figure 2). The daisy chain consists of gold metal traces on each silicon substrate connected with spring contacts. At $250 \mathrm{~mA}$, stable, but slightly decreasing resistances are observed (Figure 3). A slight decrease in the resistance with time is typical of gold contacts [15]. After $1700 \mathrm{~h}$ a failure is observed (resistance went open), and non-destructive confocal infrared inspection into the chip shows that a chip trace had failed. No spring failures are found, even in the regions predicted to be high current density. The trace has an average current density $3 \times$ higher than the spring average, and appears to fail first. All 134 spring contacts conduct $250 \mathrm{~mA}$ for $1700 \mathrm{~h}$ without failure, corresponding to an average current density of $2 \times 10^{5} \mathrm{~A} / \mathrm{cm}^{2}$ in each pair of springs. This suggests that the springs should perform well in the future when we package a $355 \mathrm{~W}$ processor with an average of $90 \mathrm{~mA}$ per contact [13].

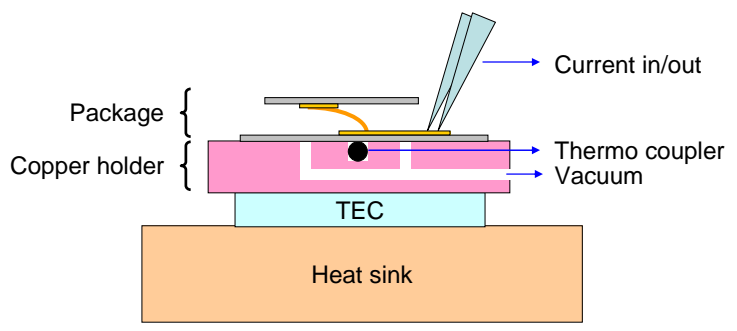

Figure 2. High current test setup. Silicon-silicon flip chip package with micro-springs on a temperature controlled stage is subject to DC current. No backside cooling structures are used on the package.
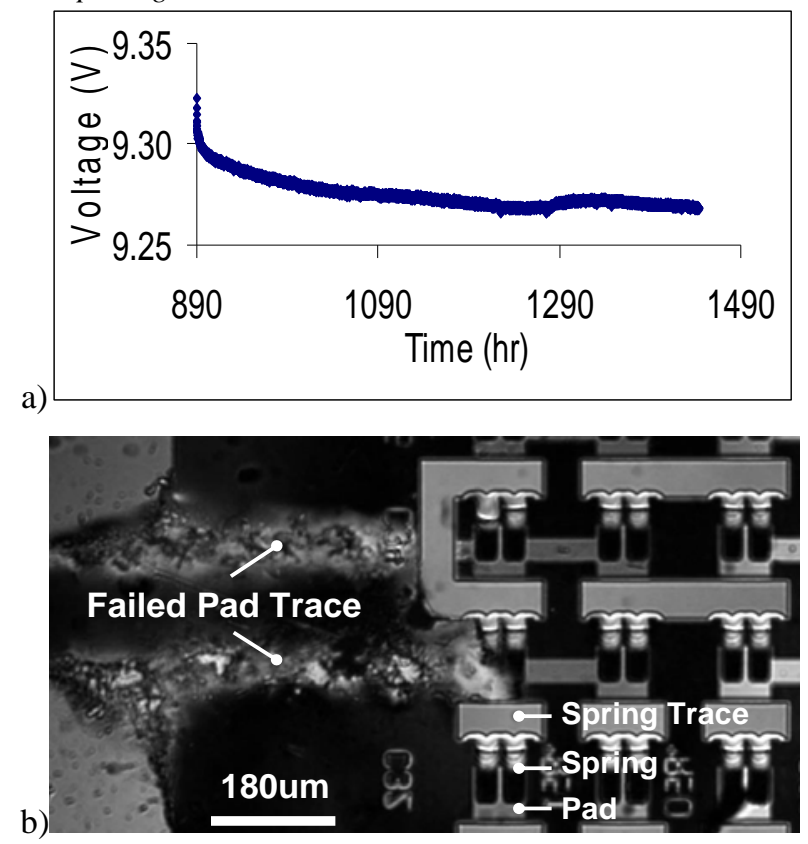

Figure 3. a) Four-wire measured voltage of a daisy chain (134 contacts in series) at $250 \mathrm{~mA}$ and $65{ }^{\circ} \mathrm{C}$, showing stable resistance values. b) IR image into the package, showing failure of the trace metal and clean spring contacts.

To try and fail the spring contact, higher current is used. One ampere current is forced from $I_{\text {in }}$ to $I_{\text {out }}$. The resistance is observed to be stable at $\sim 9.5 \Omega$ and then failed after 181 hours
(Figure 4). The spring tip and body regions are severely damaged. The spring anchor region is intact.
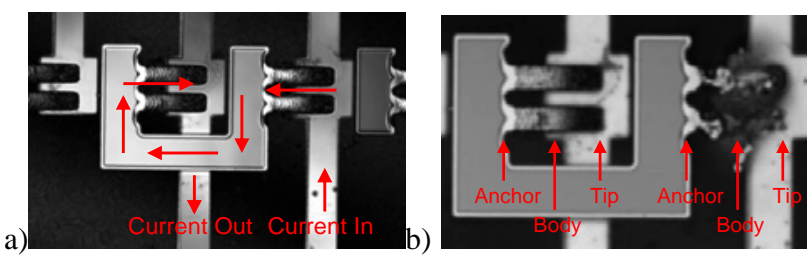

Figure 4. a) Initial image of 2-contact daisy chain. b) final image after 1 amp and $181 \mathrm{hrs}$ at $65{ }^{\circ} \mathrm{C}$, showing a failed spring on the right.

\section{TEMPERATURE MAPPING}

Temperature maps were measured while different DC currents were applied. The temperatures were stable after less than a second and the images were recorded within a few minutes of changing the current. The stage was maintained at $65{ }^{\circ} \mathrm{C}$. A hot spot at the corner of the bottom spring (near the current source) was observed (Figure 5). The trace connecting the spring was observed to heat as well as the anchor region of the springs. Less than a degree of increase in temperature was observed anywhere in the contact structure, including the hotspot on the tip, for currents up to $250 \mathrm{~mA}$. The spatial resolution of the imager is $2.8 \mu \mathrm{m}$. At $500 \mathrm{~mA}$ the tip corner temperature increased a few degrees and by $800 \mathrm{~mA}$ was over $100{ }^{\circ} \mathrm{C}$. The peak temperature increase of the anchor was also a few degrees at $500 \mathrm{~mA}$ and approximately $10{ }^{\circ} \mathrm{C}$ at $800 \mathrm{~mA}$ (Table 1). Large temperature rises can lead to asperity heating, material melting and transfer, increased constriction resistance, more heating, and eventually failure, while low temperature increases are associated with stable contacts [16].

a)
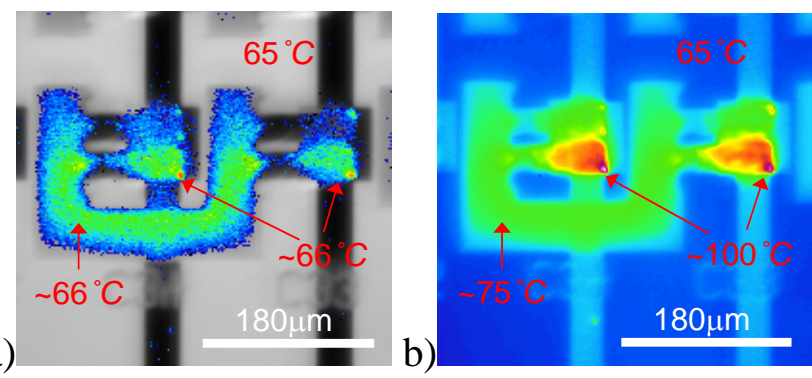

Figure 5. IR thermal image of two-wire test structure at $250 \mathrm{~mA}$ (a) and $800 \mathrm{~mA}(\mathrm{~b})$. The figures have different temperature scales.

temperatuer increase $\left[{ }^{\circ} \mathrm{C}\right]$

\begin{tabular}{|c|c|c|}
\hline current $[\mathrm{mA}]$ & tip corner & anchor corner \\
\hline 10 & $<1$ & $<1$ \\
\hline 150 & $<1$ & $<1$ \\
\hline 250 & $<1$ & $<1$ \\
\hline 500 & 8 & 5 \\
\hline 800 & 35 & 10 \\
\hline
\end{tabular}

Table 1. Observed temperature increase of tip corner and anchor corner.

The qualitative current distribution was observed through a laser excitation imaging technique (LSIM, Laser Signal Injection Microscope) synchronized with a current measurement, also 
showing high current densities at the bottom tip corner and the traces (Figure 6).

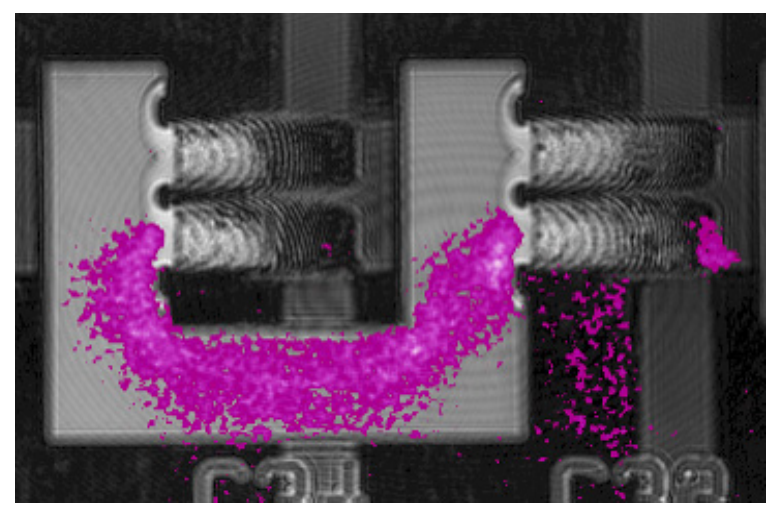

Figure 6. Observed current distribution.

\section{MODELING}

Previously we modeled a single contact 4-wire test structure and fitted to measurements to determine the effective resistance components of the spring [7]. In one contact (two springs), the interface resistance between the spring tips and the pad chip metal was estimated at 11-41 $\mathrm{m} \Omega$. This information was combined with known dimensions to build a multilayer 3D finite element model (COMSOL) of the 2-contact daisy chain inside of the package used for high current tests. At $800 \mathrm{~mA}$, the model predicts a peak current density of $\sim 1.1 \times 10^{7} \mathrm{~A} / \mathrm{cm}^{2}$ at the corner of the bottom tip (Figure 7). About $63 \%$ of the current is passing through the bottom spring and 27\% through the top spring, due to asymmetry of the geometry (Figure 8). This suggests that rotating the spring contacts $90^{\circ}$ with respect to the pad trace so both tips see the same current distribution could lower the peak current density. This $90^{\circ}$ rotation design was simulated and the current crowding spots were located in the anchor corner (Figure 9). The spring tip is not highest current density region anymore, suggesting that spring softening due to anchor weakening could be a relevant failure mechanism. Note that the anchor hot spots are not symmetrical, due to the spring chip trace connecting the two neighboring contacts. In a symmetric geometry, such as the spring anchor sitting on a large metal via connecting to a lower level of metal routing, lower peak current is expected.

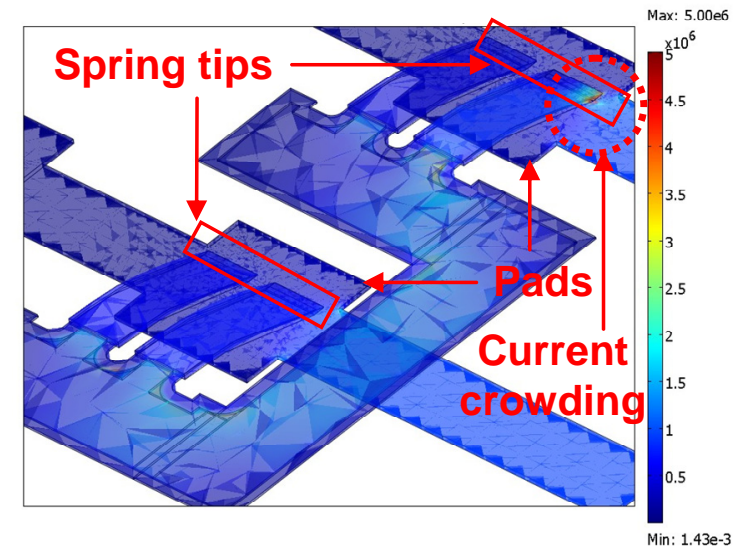

Figure 7. a) FEM model of current density distribution of 2contact daisy chain at $800 \mathrm{~mA}$.

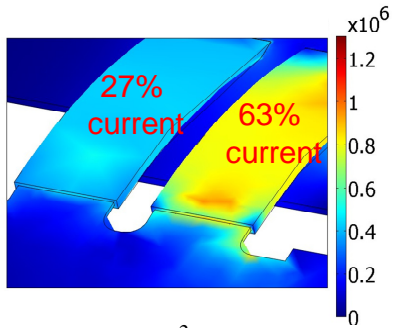

Figure 8. Current density $\left(\mathrm{A} / \mathrm{cm}^{2}\right)$ of the spring anchors and body at $800 \mathrm{~mA}$. The right spring takes $63 \%$ of the current.

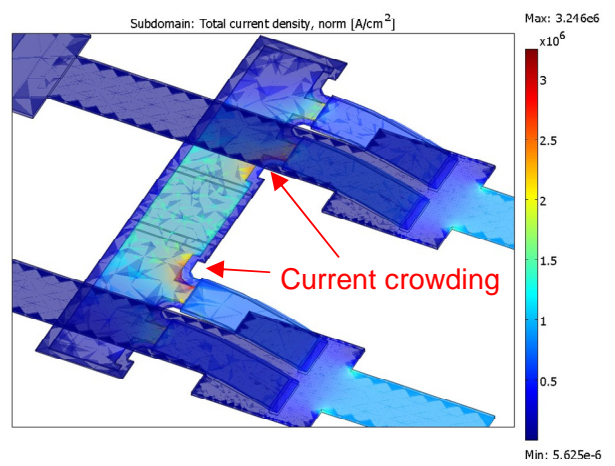

Figure $9.90^{\circ}$ rotation (compared to Figure 7)of spring contacts at $800 \mathrm{~mA}$. The spring tips have lower current density than the anchor corners.

\section{FORCE MEASUREMNTS}

The electrical integrity of the spring contact depends strongly on maintaining adequate force, unlike metallurgical bonded contacts likes solder or stud bumps. The force is generated from the bending moment of the entire spring, but peak stress is at the anchor. The mechanical integrity of the springs was previously indirectly measured by observing stable 4 -wire resistances in 0 ${ }^{\circ} \mathrm{C}-100{ }^{\circ} \mathrm{C}$ thermocycling and $85 \mathrm{RH} / 85^{\circ} \mathrm{C}$ humidity tests [6-7]. However these studies were performed at low (1 mA) or zero current. Modeling also shows current crowding in the anchor (Figure 8). Temperature imaging shows increases in the anchor temperature at $500 \mathrm{~mA}$. In a die to substrate package, such as silicon to organic, the temperature increases could be more severe because of reduced substrate thermal conductivity. If the force of the spring weakens, the tip interface contact resistance could increase and more quickly fail, such as thermal runaway.

Possible force softening under high current heating was studied with a three contact 4-wire resistance measurement previously used for electrical measurements only [7]. This resistance measurement setup was integrated with a force scale to enable simultaneous force vs resistance measurements with $\sim 1 \mathrm{mg}$ resolution (more sensitive setups are possible). Current steps of $100 \mathrm{~mA}$ were applied but no force or resistance change was observed, suggesting the absence of any immediate heat induced force softening (Figure 10). Higher current tests were not compatible with the existing setup.

Measurements of the spring height as a function of temperature show the spring to be very stable, as the height does not change until heated by $300^{\circ} \mathrm{C}$ (Figure 11). The symmetry of the spring structural layers is believed to facilitate this. In contrast, stress induced self assembly springs made with bimorphs are inherently temperature sensitive. Future work includes investigating liftheights after being under load for extended times, to discern when creep effects are relevant. 


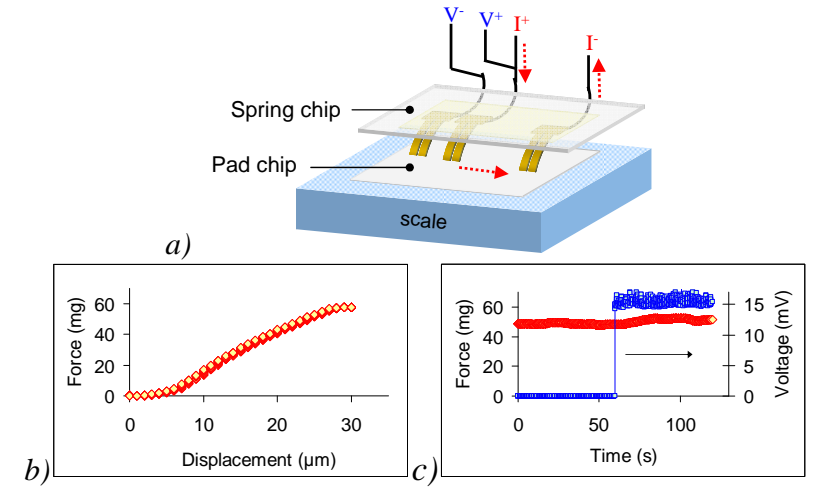

Figure 10. a) Single contact test structure schematic. The device under test is the center pair of springs and the pad sits on a force scale to simultaneously measure spring force. b) Force curve for the 6 spring test structure and c) A $100 \mathrm{~mA}$ current step (at $25 \mu \mathrm{m}$ compression), showing no force change.

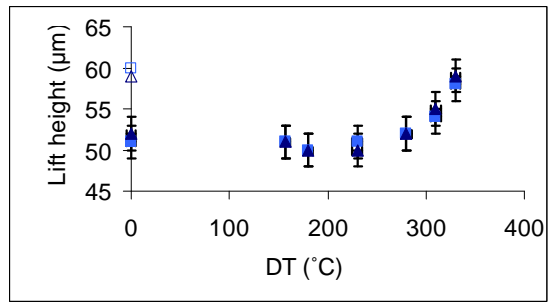

Figure 11. Measured lift height vs. temperature, showing stable heights until $300^{\circ} \mathrm{C}$.

\section{CONCLUSIONS}

Gold to gold microspring pressure contacts in silicon-silicon packages are capable of carrying $250 \mathrm{~mA}\left(2 \times 10^{5} \mathrm{~A} / \mathrm{cm}^{2}\right.$ average current density) for more than 1700 hours and $1 \mathrm{~A}\left(1 \times 10^{6} \mathrm{~A} / \mathrm{cm}^{2}\right.$ average current density) for 181 hours at $65{ }^{\circ} \mathrm{C}$. Finite element simulation of the current density distribution matches well with observed hot spot locations and failure locations. An improved design is proposed to reduce density by 40 times at the spring tip. No mechanical softening of the spring is observed for $100 \mathrm{~mA}$ current stressing. Recently we have flip-chip-assembled active silicon IC die onto an organic substrate with $2 \mathrm{~d}$ array spring contacts [17], and plan to next study the high current properties of this package.

\section{ACKNOWLEDGEMENTS}

We thank Lai Wong for fabrication support, and Quantum Force Instruments and Olympus for use of measurement tools.

\section{REFERENCES}

[1] E. M. Chow, C. Chua, T. Hantschel, K. Van Schuylenbergh, and D. K. Fork, "Pressure contact micro-springs in small pitch flip-chip packages," IEEE Transactions on Components and Packaging Technologies, vol. 29, pp. 796-803, (2006).

[2] E. M. Chow, D. K. Fork, C. L. Chua, K. V. Schuylenbergh, and T. Hantschel, "Wafer-level packaging with soldered stress-engineered microsprings," IEEE Transactions on Advanced Packaging, vol. 32, pp. 372-378, (2009).

[3] C. L. Chua, D. K. Fork, K. V. Schuylenbergh, and J.-P. Lu, "Out-of-plane high-Q inductors on low-resistance silicon,"
Journal of Microelectromechanical Systems, vol. 12, pp. 989-995, (2003).

[4] M. A. Rosa, D. De Bruyker, A. R. Volkel, E. Peeters, and J. Dunec, "A novel external electrode configuration for the electrostatic actuation of MEMS based devices,” IOP Journal of Micromechanics and Microengineering, vol. 14, pp. 446451, (2004).

[5] T. Hantschel, E. M. Chow, D. Rudolph, and D.K. Fork, "Stressed metal probes for atomic force microscopy," Applied Physics Letters, vol. 81, pp. 3070-3072, (2002).

[6] I. Shubin, E. M. Chow, J. Cunningham, D. DeBruyker, C. Chua, B. Cheng, J. C. Knights, K. Sahasrabuddhe, Y. Luo, A. Chow, J. Simons, A. V. Krishnamoorthy, R. Hopkins, R. Drost, R. Ho, D. Douglas, J. Mitchell, "Novel packaging with rematable spring interconnect chips for MCM," 59th Electronic Components and Technology Conference (ECTC), May 26-29, (2009), pp.1053 - 1058.

[7] B. Cheng, E. M. Chow, D. DeBruyker, C. Chua, K. Sahasrabuddhe, I. Shubin, J. Cunningham, Y. Luo and A. V. Krishnamoorthy, "Microspring Characterization and Flip Chip Assembly Reliability,” 42th International Microelectronics and Packaging Society (IMAPS), November 1-5, (2009).

[8] D. Yang, Y. C. Chan and K. N. Tu, "The time-dependent melting failure in flip chip lead-free solder interconnects under current stressing," Applied Physics Letters, vol. 93, 041907, (2008).

[9] K. N. Tu," Recent advances on electromigration in verylarge-scale-integrationof interconnects,” J. of Applied Physics, vol. 94, pp. 5451-5473, (2003).

[10] Chih Chen and S. W. Liang, "Electromigration issues in lead-free solder joints”, J Mater Sci: Mater Electron, vol. 18, pp. 259-268, (2007).

[11] "Interconnect," The International Technology Roadmap for Semiconductors, (2007) Edition.

[12] W.-S. Kwon and K.-W. Paik, ”High Current Induced Failure of ACAs Flip Chip Joint," 52th Electronic Components and Technology Conference (ECTC), May 28-31, (2002), pp. 1130-1134.

[13] J. Schauer, N. Pinckney, N. Nettleton, and D. Popovic, ”A test platform for the thermal electrical and mechanical characterization of packages," 42nd International Symposium on Microelectronics (IMAPS), November 1-5, (2009).

[14] J. Maciel, S. Majumder, R. Morrison, J. Lampen, "Lifetime characteristics of ohmic MEMS switches," Proceedings of the SPIE - The International Society for Optical Engineering, vol. 5343, pp. 9-14, (2003).

[15] O. Rezvanian, C. Brown, M. A. Zikry, A. I. Kingon, J. Krim, D. L. Irving, and D. W. Brenner, "The role of creep in the time-dependent resistance of ohmic gold contacts in radio frequency microelectromechanical system devices", J. Applied Physics, vol. 104, 024513, (2008).

[16] Christopher John Brown, "Impact of environmental conditions on the contact physics of gold contact RF Microelectromechanical Systems (MEMS) switches,” Doctor of Philosophy thesis, (2008).

[17] I. Shubin, E. M. Chow, J. Cunningham, D. Debruyker, M. Grier, B. Cheng, N. Nettleton, G. Anderson, J. Simons, D. Douglas, "A Package Demonstration with Solder Free Compliant Flexible Interconnects," 60th Electronics Components and Technology Conference (ECTC), accepted for publication, (2010). 